\title{
Relative Competitiveness of Nimblewill (Muhlenbergia schreberi) with Tall Fescues and Kentucky Bluegrass
}

\author{
Pedro V. D. Moraes', Willian W. Witt², Timothy D. Phillips², Patricia Rossi¹, \\ Luis E. Panozzo ${ }^{3}$ \\ ${ }^{1}$ Federal Technologic University of Paraná, UTFPR, Dois Vizinhos, Brazil \\ ${ }^{2}$ University of Kentucky, Lexington, USA \\ ${ }^{3}$ Federal University of Pelotas, Pelotas, Brazil \\ Email:pvdmoraes@gmail.com
}

Received 7 November 2014; revised 2 December 2014; accepted 10 December 2014

Copyright (C) 2014 by authors and Scientific Research Publishing Inc.

This work is licensed under the Creative Commons Attribution International License (CC BY). http://creativecommons.org/licenses/by/4.0/

(c) (i) Open Access

\begin{abstract}
Nimblewill (Muhlenbergia schreberi) is a warm-season perennial grass (weed) native to the United States and Canada with low palatability. This species is dominant in many horse pastures in which bluegrass (Poa pratensis) is the primary forage. Tall fescues infected with endophyte fungae gives tall fescue plants greater competitividade ability and enviromental stress tolerance than their noninfected counterparts. The purpose of this study was to compare the relative competitiveness of nimblewill with bluegrass and tall fescues (Lolium arundinaceum) with or without endophytic fungi (strain AR584) through experiments using a replacement series design. Replacement series experiments were conducted in pots to evaluate the growth of species in a pure stand and in a mix stand with variables rates. Species competitiveness was evaluated based on the relative yield and relative yield total (and competitiveness index) of the dry weight of shoots from species grown together. Nimblewill was found to be more competitive than bluegrass, and all tall fescues were more competitive than nimblewill. Our results demonstrated that the presence of endophytes in three different tall fescues did not alter the competitiveness of these fescues with nimblewill, but the tall fescue Kentucky 31 was more competitive between tall fescues. Based on our finding, we concluded that fescues are recommended, especially without the endophytic fungi to suppress nimblewill in implantation of pastures to horses.
\end{abstract}

\section{Keywords}

Competition, Pastures, Weed, Endophytic Fungi

How to cite this paper: Moraes, P.V.D., Witt, W.W., Phillips, T.D., Rossi, P. and Panozzo, L.E. (2014) Relative Competitiveness of Nimblewill (Muhlenbergia schreberi) with Tall Fescues and Kentucky Bluegrass. American Journal of Plant Sciences, 5, 3777-3787. http://dx.doi.org/10.4236/ajps.2014.526395 


\section{Introduction}

Tall fescue is the predominate cool-season pasture species of the eastern United States and over $90 \%$ of the tall fescue pastures in the United States are believed to be infected with the fungal endophyte [1], for example, the tall fescue cultivar "KY 31" is a dominant forage grass for beef animals in Kentucky and surrounding states and frequently contains the natural race of the endophytic fungus (Neotyphodium coenophialum). Cultivars have been developed that are endophyte free. The importance of tall fescue as a pasture grass is diminished when infected with the fescue endophyte [2] and presence of nimblewill weed.

Nimblewill (Muhlenbergia schreberi) is a prominent weed in tall fescue (Lolium arundinaceum) and Kentucky bluegrass (Poa pratensis) pastures as well as hay fields. It is a native warm-season $\left(\mathrm{C}_{4}\right)$ perennial grass that thrives in lightly shaded areas and easily invades lawns, waste areas, and other disturbed sites [3]. Controlling nimblewill with herbicides is difficult and the weed presents a serious problem in horse pastures. Due to its unpalatability to horses and the lack of selective herbicides this weed decreases the grazing quality of pastures [4].

Losses in crop quantity or quality from the interactions among weeds and crops form the basis of modern weed science. Weeds can reduce the quantity and the stand life of desirable forage plants in pasture and hayfields. These unwanted plants are often more aggressive than existing or desired forage species and compete for light, water and nutrients.

When plant species grow together, they often respond to environmental factors differently than when grown separately. Studies of weed and crop competition can be used to predict yield loss and decision aids to obtain optimum levels or critical periods of weed control. Competition during pasture establishment is affected by several factors, including seed weight, seedling vigor, and seedling morphology [5]. Therefore, using competitive cultivars to supplement weed management can reduce weed control inputs, be economical, and is perceived as environmentally benign [6]. Therefore, the use of forage crops with increased aggressiveness may be an alternative to contain the spread of nimblewill in pastures,

Little is known about the competitive interactions between tall fescue or Kentucky bluegrass and nimblewill. The methods used to study plant competition must consider density, spatial arrangement as well as proportion, and can be used to answer questions about interspecific and intraspecific competition [7]. Results of one study [8] indicated that endophyte infection decreased the performance of perennial ryegrass in both intra- and interspecific competition. In other studies, [9] found that endophyte infection had a significant positive effect on ryegrass shoot and root growth, because the plants tended to accumulate more biomass and soluble sugar in the sheath and root than plants that were endophyte free. Endophyte-infected plants have a physiological mechanism that permits better growth, survival, and competitiveness under stressful growth conditions than plants endophyte free [10].

No research has been conducted on the influence of endophyte infection on the competition between coolseason and warm-season grasses. Because endophyte-infected grasses are extensively used as groundcover in soil conservation, it is important to know how endophyte infection influences the establishment and competition with other co-occurring species [11].

The aim of this study was to compare the relative competitiveness of nimblewill with Kentucky bluegrass and tall fescue through experiments using a replacement series design.

\section{Materials and Methods}

\subsection{Plant Material}

The replacement series experiment was conducted in May 2009 and 2010 in a greenhouse in Lexington, Kentucky, USA $\left(38^{\circ} 5^{\prime} \mathrm{N}, 84^{\circ} 44^{\prime} \mathrm{W}\right)$.

The grass species used in the experiment were:

1) Kentucky bluegrass;

2) Tall fescue Kentucky 31 containing a common toxic endophyte;

3) Tall fescue KYFA 9821, with a new endophyte strain AR584;

4) Tall fescue EFKYFA 9821 without the endophyte (strain AR584);

5) Tall fescue KYFA 9301 with the strain AR584;

6) Tall fescue EFKYFA 9301without (strain AR584);

7) Nimblewill. 
The treatments in the pots comprised a growth pasture test, in a pure stand and in mixed cultures at five varying proportions (16:0, 12:4, 8:8, 4:12, and 0:16).

\subsection{Preparation of Monoculture and Mixtures of These Species}

The species were seeded in different intervals: Kentucky bluegrass (Poa pratensis) was sown first, followed by nimblewill after $1 \mathrm{~d}$ and fescue after $3 \mathrm{~d}$. This method was adopted to exclude the effects of individual species' germination speed on the competition, and to obtain seedlings of all species at the same phenological stage. Fescues, Kentucky bluegrass and nimblewill were seeded in trays and transplanted to pots $5 \mathrm{~d}$ after germination. To ensure that transplanting density would be conducive to interference, preliminary studies were conducted before in monocultures and were determined to be 16 plants per plastic pot (data not shown). The transplanting proportions of pasture were as follows: nimblewill 16:0, 12:4, 8:8, 4:12, and 0:16 plants per pot (from 100\% to 0\% nimblewill), in a completely randomized block design with four replications

Monoculture and mixtures of these species were transplanted in plastic pots filled with $1000 \mathrm{~g}$ of local soil (Maury-Kentucky bluegrass silt loam complex [fine, mixed, active, mesic Typic Paleudalfs]) with 7\% sand, 75\% silt, $18 \%$ clay, and $2.5 \%$ organic matter and a $\mathrm{pH}$ of 6.8 . The transplanted plants were arranged in circles within the pots, which were placed on trays, filled with approximately $2 \mathrm{~cm}$ water, and maintained until $50 \mathrm{~d}$ after emergence (DAE) under natural conditions of light and a mean temperature of $25^{\circ} \mathrm{C}$. Pots were randomized weekly to prevent the creation of microclimates.

After $50 \mathrm{DAE}$, the aerial parts of plants were cut at the soil surface, separated by species, counted, placed into paper sacks, and dried in a forced-air oven at $\pm 70^{\circ} \mathrm{C}$ for $72 \mathrm{~h}$.

\section{Measurements.}

Species competition was evaluated based on the relative yield (RY) and relative yield total (RYT) of the shoots' dry mass. RY is the ratio between the weight of the species in the mixture and the weight of the species in monoculture. RYT is the total relative yield of the two associated species per unit area. RYT $=1$ indicates that species A and B are making demands on the same limiting resources. RYT $>1$ indicates nesting or avoidance of competition between two species (greater biomass productivity per unit area in a mixed vs. monoculture). RYT $<1$ indicates mutual antagonism between species A and B (less biomass productivity per unit area in a mixed vs. monoculture) [6] [12] [13].

The procedure for statistical analysis of RY was made by calculating the difference in the values of RY (DRY) obtained as $25 \%, 50 \%$, and $75 \%$ of the values belonging to the hypothetical straight line in their proportions.

The indices of competitive ratio (CR), relative crowding coefficient (K), and aggressiveness (A) were calculated and are as follows: $\mathrm{CR}$ represents the comparative growth of genotype $\mathrm{X}$ compared to genotype $\mathrm{Y}$, $\mathrm{K}$ indicates the relative dominance of one genotype over the other, and A shows which genotype is more aggressive. Thus, $\mathrm{CR}, \mathrm{K}$, and $\mathrm{A}$ indicate which genotype in each mixture was more competitive [12].

If $C R>1, K_{A}>K_{B}$, and $A>0$, then genotype $A$ is more competitive than $B$; however, if $C R<1, K_{A}<K_{B}$, and $A<0$, genotype $B$ is the more competitive of the two [12]. To calculate these indices the 50:50 ratio of species was used with the following equations, as suggested by [14]:
1) $C R=R Y_{A} / R Y_{B}$;
2) $K_{A}=R Y_{A} /\left(1-R Y_{A}\right)$;
3) $\mathrm{K}_{\mathrm{B}}=R Y_{\mathrm{B}} /\left(1-R Y_{\mathrm{B}}\right)$;
4) $A=R Y_{A}-R Y_{B}$.

The Student's $t$ test was used for DRY, RYT, CR, K, and A analyses [12]. The differences between DRY and A, with the average being equal to $0(\mathrm{Ho}=0)$; between RYT and $\mathrm{CR}$, with the averages equal to one $(\mathrm{Ho}=1)$; and for $\mathrm{K}$, in which the mean differences between $\mathrm{K}_{\mathrm{A}}$ and $\mathrm{K}_{\mathrm{B}}$ were equal to $0\left(\mathrm{Ho}=\left(\mathrm{K}_{\mathrm{A}}-\mathrm{K}_{\mathrm{B}}\right)=0\right)$ were considered as the null hypotheses. The criterion for considering the different curves of the hypothetical straight lines had to be at least two significant differences using the $t$ test [15]. Similarly, for CR, K, and A, it was considered the existence of differences in competitiveness when at least two of them were significantly different using the $t$ test.

\section{Statistical Analysis}

The data for shoot dry mass, expressed in mean values per plant, were subjected to normality test and ANOVA. 
Treatment means were compared by parametric Dunnett's test, considering the monocultures as the control for comparison. All tests were performed at a 5\% probability. The data processing was performed with SAS software [16].

\section{Results}

The replacement diagrams illustrated in Figure 1 are interpreted based on the shape of the curves derived from the shoot dry mass of each species. This competition model shows the reciprocal effect of each forage species and nimblewill at each species proportion. A convex line indicates that one species gained more resources at the expense of the other; a concave line indicates that one species lost to the other in the competition for resources.

The replacement series experiment with Kentucky bluegrass and nimblewill showed that the RY of the dry mass of nimblewill shoots was indicated by the convex line and that of Kentucky bluegrass shoots by the concave line (Figure 1(a)). The Kentucky bluegrass was at a disadvantage in capturing soil resources for growth when the mixture $75 \%$ and $50 \%$ nimblewill.
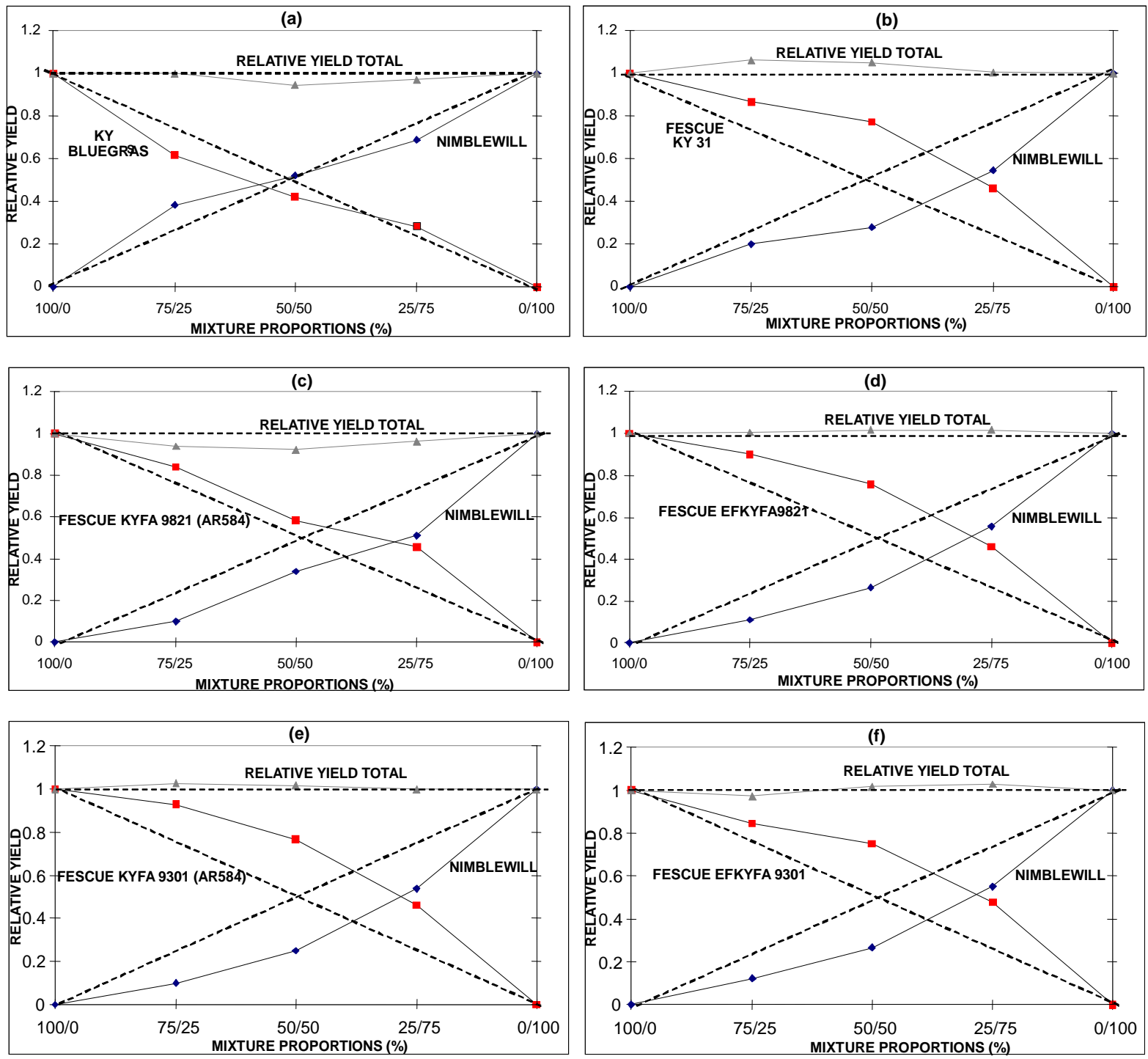

Figure 1. Replacement series diagrams of relative yield for shoot dry matter of Kentucky bluegrass (a), tall fescue KY 31 (b), tall fescue KYFA 9821 (AR584) (c), tall fescue EFKYFA 9821 (d), tall fescue KYFA 9301 (AR584) (e), tall fescue EFKYFA 9301 (f), and nimblewill, $50 \mathrm{~d}$ after transplanting in various proportions in a greenhouse in Lexington, Kentucky, USA, average 2009-2010. 
At 25\% nimblewill, the Kentucky bluegrass made better use of soil resources, was more competitive with nimblewill, and demonstrated that it thrives more in interspecific competition (Table 1). The data indicate that nimblewill was a superior competitor when grown mixed with Kentucky bluegrass.

RYT was equal to one in the 75:25 (Kentucky bluegrass vs. nimblewill) mixture, showing that there was competition for the environmental resources between Kentucky bluegrass and nimblewill. At 50:50 and 25:75, RYT was less than 1, indicating multiple damage to both species (Figure 1, Table 1). RYT in the proportion tested showed no difference considering that the different curves of the hypothetical lines have to show at least two significant differences by $t$ test (Figure 1, Table 1) [15].

When all tall fescues were grown mixed with nimblewill, there were increases in dry mass per plant in all tall fescue shoots. Each tall fescue in the experiment showed similar behavior in competition with nimblewill. RY of nimblewill was significantly less than what was expected from that in the pure stand, while RY of all tall fescues was unaffected. This implies that nimblewill was more affected by interspecific competition, indicating a competitive relationship with all tall fescues (Figures 1(b)-(f)).

The results related to the 50:50 ratio of each species are considered the critical point for analyses of a replacement series experiment, because they clearly show the best competitor when the species are planted in equal proportions [16].

RY of the dry mass of nimblewill shoots (concave line) was less than what was expected from that in the pure stand, while RY of tall fescue Kentucky 31 was unaffected (convex line) in all mixture proportions (Figure 1(b)). In Table 2, we see than tall fescue "Kentucky 31" was more competitive than nimblewill, because it showed a greater difference in RY than nimblewill in all mixture proportions; both were statistically different when considering that the different curves of the hypothetical straight lines must be at least two significant differences by $t$ test [15].

RYT describes the mutual relationships of paired species, and indicates that the tall fescue "Kentucky 31" competed with nimblewill and made the same demands on environmental resources (RYT value near 1 or equal to 1) (Figure 1(b) and Table 2).

Table 1. Average of the effect of proportions of Kentucky bluegrass and nimblewill plants on the differences in relative yield (DRY) and relative yield total (RYT) on the dry mass of shoots under greenhouse conditions, Lexington, KY, USA, 2009-2010.

\begin{tabular}{|c|c|c|c|}
\hline & \multicolumn{3}{|c|}{ Proportion of plants (Kentucky bluegrass vs. nimblewill) } \\
\hline & \multicolumn{3}{|c|}{ Dry mass (g/plant) } \\
\hline & $75: 25$ & $50: 50$ & $25: 75$ \\
\hline DRY Kentucky bluegrass & $-0.13( \pm 0.04)^{*}$ & $-0.80( \pm 0.05)$ & $0.03( \pm 0.01)$ \\
\hline DRY nimblewill & $0.14( \pm 0.02)^{*}$ & $0.02( \pm 0.05)$ & $-0.06( \pm 0.02)$ \\
\hline RYT & $1.00( \pm 0.06)$ & $0.94( \pm 0.07)$ & $0.97( \pm 0.03)$ \\
\hline
\end{tabular}

*Significance for Student's $t$ test: $\mathrm{p} \leq 0.05$.

Table 2. Average of the effect of differing proportions of tall fescue Kentucky 31 (KY 31) and nimblewill plants on the difference in relative yield (DRY) and relative yield total (RYT) for the dry mass of shoots under greenhouse conditions, Lexington, KY, USA, 2009-2010.

\begin{tabular}{|c|c|c|c|}
\hline & \multicolumn{3}{|c|}{ Proportion of plants (tall fescue KY 31 vs. nimblewill) } \\
\hline & \multicolumn{3}{|c|}{ Dry mass (g/plant) } \\
\hline & $75: 25$ & $50: 50$ & 25:75 \\
\hline DRY fescue KY 31 & $0.11( \pm 0.03)^{*}$ & $0.27( \pm 0.04)^{*}$ & $0.21( \pm 0.04)^{*}$ \\
\hline DRY nimblewill & $-0.05( \pm 0.01)^{*}$ & $-0.22( \pm 0.01)^{*}$ & $-0.21( \pm 0.05)^{*}$ \\
\hline RYT & $1.06( \pm 0.03)$ & $1.05( \pm 0.04)$ & $1.01( \pm 0.08)$ \\
\hline
\end{tabular}

*Significance for Student's $t$ test: $\mathrm{p} \leq 0.05$. 
The tall fescue KYFA 9821 with the endophyte (strain AR584) and EFKYFA 9821 without the endophyte (convex line) had an RY of the shoot dry mass that was significantly higher than expected for all mixture combinations, and the concave line for nimblewill indicated that it was less competitive (Figure 1(c), Figure 1(d)), with a significant difference by $t$ test between tall fescues and nimblewill (Table 3 and Table 4). The tall fescue EFKYFA 9821 without the endophyte was more competitive with nimblewill than the tall fescue KYFA 9821 with the endophyte.

RYT for tall fescue KYFA 9821 with the endophyte (strain AR584) indicates competition and losses for both species (RYT < 1) in all mixture proportions (antagonism), although tall fescue was the more aggressive species (Figure 1(c), Table 3). For tall fescue EFKYFA 9821 without the endophyte when grown with nimblewill, RYT was close to one, indicating that the competition for resources between the two species was equivalent or compensatory (Figure 1(d), Table 4).

Similarly, RY of the shoot dry mass of tall fescue KYFA 9301 with the endophyte (strain AR584) and EFKYFA 9301 without the endophyte (convex line) indicated that these species were more competitive and less sensitive to competition with nimblewill (concave line). Shoot dry mass obtained from both tall fescues grown in a mixture with nimblewill was greater than expected when compared with shoot dry mass calculated from tall fescues grown in monoculture. This response suggests that tall fescue has high intraspecific competition. A similar comparison of shoot dry mass of nimblewill determined that it was less than expected when grown mixed with both tall fescues (Figure 1(e) and Figure 1(f)).

The data in Table 5 and Table 6 indicate that tall fescue KYFA 9301 with endophyte (strain AR584) and tall fescue EFKYFA 9301 without the endophyte showed higher differences relative yield to shoots dry mass in all proportions of plants. The weed dry mass was lost in all proportions tested, statistically differeing, as [15].

RYT of tall fescue KYFA 9301 with the endophyte (strain AR584) and nimblewill showed that RYT was close to 1, indicating that both species make demands on the same limiting resources (Figure 1(e), Table 5). Similarly, RYT of EFKYFA 9301 without the endophyte and nimblewill is nearly one, indicating competition (Figure 1(e), Table 5).

Table 3. Average of the effect of differing proportions of tall fescue KYFA 9821 (AR584) and nimblewill plants on the difference in relative yield (DRY) and relative yield total (RYT) for shoot dry mass under greenhouse condition, Lexington, KY, USA, 2009-2010.

\begin{tabular}{|c|c|c|c|}
\hline & \multicolumn{3}{|c|}{ Proportion of plants (tall fescue KYFA 9821 (AR584) vs. nimblewill) } \\
\hline & \multicolumn{3}{|c|}{ Dry mass (g/plant) } \\
\hline & $75: 25$ & $50: 50$ & 25:75 \\
\hline DRY tall fescue KYFA 9821 (AR584) & $0.09( \pm 0.07)$ & $0.08( \pm 0.02)^{*}$ & $0.20( \pm 0.05)^{*}$ \\
\hline DRY nimblewill & $-0.15( \pm 0.03)^{*}$ & $-0.16( \pm 0.02)^{*}$ & $-0.24( \pm 0.05)^{*}$ \\
\hline RYT & $0.94( \pm 0.08)$ & $0.92( \pm 0.03)$ & $0.96( \pm 0.04)$ \\
\hline
\end{tabular}

*Significance for Student's $t$ test: $\mathrm{p} \leq 0.05$.

Table 4. Average of the effect of differing proportions of tall fescue EFKYFA 9821 and nimblewill plants on the difference in relative yield (DRY) and relative yield total (RYT) for shoot dry mass under greenhouse conditions, Lexington, KY, USA, 2009-2010.

\begin{tabular}{|c|c|c|c|}
\hline & \multicolumn{3}{|c|}{ Proportion of plants (tall fescue EFKYFA 9821 vs. nimblewill) } \\
\hline & \multicolumn{3}{|c|}{ Dry mass (g/plant) } \\
\hline & $75: 25$ & $50: 50$ & 25:75 \\
\hline DRY tall fescue EFKYFA 9821 & $0.15( \pm 0.01)^{*}$ & $0.25( \pm 0.01)^{*}$ & $0.21( \pm 0.04)^{*}$ \\
\hline DRY nimblewill & $-0.14( \pm 0.02)^{*}$ & $-0.24( \pm 0.02)^{*}$ & $-0.19( \pm 0.05)^{*}$ \\
\hline RYT & $1.01( \pm 0.02)$ & $1.02( \pm 0.02)$ & $1.02( \pm 0.07)$ \\
\hline
\end{tabular}

*Significance for Student's $t$ test: $\mathrm{p} \leq 0.05$. 
In Figure 1, we see that all tall fescues with or without the endophyte have the same curves. Tall fescue performed better in a mixed culture, but the weed did not. This showed that the presence or absence of the endophyte fungi did not interfere with the competition with nimblewill. [17] reported that the more-aggressive species in a mixture increased in weight with increased proportion of the less-aggressive species.

The intersection for equivalency shifted to the left, indicating that nimblewill had a disadvantage in capturing resources for its growth in all mixture proportions (Figure 1). The competition between the two species occurred by resource of from the environment, begin used more efficiently by each tall fescue, proving that it is more competitive than nimblewill in all proportions tested. Tall fescue can strongly compete with many native species in USA and Canada.

Table 7 shows that all tall fescues were more competitive than nimblewill according to variable shoot dry mass indicated by the competitive hierarchy indices of $\mathrm{CR}>1, \mathrm{~K}_{\mathrm{A}}>\mathrm{K}_{\mathrm{B}}$, and $\mathrm{A}>0$, which were established by [12]. The exception was Kentucky bluegrass, which was less competitive than nimblewill according to the competitive hierarchy indices of $\mathrm{CR}<1, \mathrm{~K}_{\mathrm{A}}<\mathrm{K}_{\mathrm{B}}$, and $\mathrm{A}<0$.

Table 5. Average of the effect of differing proportions of tall fescue KYFA 9301 (AR584) and nimblewill plants on the difference in relative yield (DRY) and relative yield total (RYT) for shoot dry mass under greenhouse conditions, Lexington, KY, USA, 2009-2010.

\begin{tabular}{cccc}
\hline & \multicolumn{2}{c}{ Proportion of plants (tall fescue KYFA 9301 (AR584) vs. nimblewill) } \\
\cline { 2 - 3 } & \multicolumn{3}{c}{ Dry mass (g/plant) } \\
\hline DRY tall fescue KYFA 9301 (AR584) & $0.18( \pm 0.04)^{*}$ & $\mathbf{5 0 : 5 0}$ & $\mathbf{2 5 : 7 5}$ \\
DRY nimblewill & $-0.15( \pm 0.01)^{*}$ & $0.27( \pm 0.02)^{*}$ & $0.21( \pm 0.05)^{*}$ \\
RYT & $1.03( \pm 0.04)$ & $-0.25( \pm 0.01)^{*}$ & $-0.21( \pm 0.07)$ \\
\hline
\end{tabular}

*Significance for Student's $t$ test: $\mathrm{p} \leq 0.05$.

Table 6. Average of the effect of differing proportions of tall fescue EFKYFA 9301 and nimblewill plants on the difference in relative yield (DRY) and relative yield total (RYT) for shoot dry mass under greenhouse conditions, Lexington, KY, USA, 2009-2010.

\begin{tabular}{|c|c|c|c|}
\hline & \multicolumn{3}{|c|}{ Proportion of plants (tall fescue EFKYFA 9301 vs. nimblewill) } \\
\hline & \multicolumn{3}{|c|}{ Dry mass (g/plant) } \\
\hline & $75: 25$ & $50: 50$ & 25:75 \\
\hline DRY tall fescue EFKYFA 9301 & $0.10( \pm 0.05)$ & $0.25( \pm 0.02)^{*}$ & $0.23( \pm 0.03)^{*}$ \\
\hline DRY nimblewill & $-0.13( \pm 0.01)^{*}$ & $-0.23( \pm 0.02)^{*}$ & $-0.20( \pm 0.02)^{*}$ \\
\hline RYT & $0.97( \pm 0.05)$ & $1.01( \pm 0.03)$ & $1.03( \pm 0.03)$ \\
\hline
\end{tabular}

*Significance for Student's $t$ test: $\mathrm{p} \leq 0.05$.

Table 7. Replacement series indices calculated for dry mass of tall fescue, Kentucky bluegrass, and nimblewill plants for competitive ratio (CR), relative crowding coefficient (k), and aggressiveness (A), average two years, Lexington, KY, USA, 2009-2010.

\begin{tabular}{|c|c|c|c|c|}
\hline Pasture & CR & Ka (pasture) & Kb (nimblewill) & $\mathbf{A}$ \\
\hline Kentucky bluegrass & $0.84( \pm 0.12)$ & $0.78( \pm 0.16)$ & $1.14( \pm 0.22)$ & $-0.10( \pm 0.07)$ \\
\hline Fescue KY 31 & $2.82( \pm 0.21)^{*}$ & $3.97( \pm 0.98)^{*}$ & $0.38( \pm 0.02)^{*}$ & $0.50( \pm 0.05)^{*}$ \\
\hline Fescue KYFA 9821 (AR584) & $1.17( \pm 0.07)$ & $0.68( \pm 0.02)^{*}$ & $0.53( \pm 0.03)^{*}$ & $0.06( \pm 0.02)$ \\
\hline Fescue EFKYFA 9821 & $1.42( \pm 0.01)^{*}$ & $0.75( \pm 0.03)^{*}$ & $0.43( \pm 0.01)^{*}$ & $0.13( \pm 0.00)^{*}$ \\
\hline Fescue KYFA 9301 (AR584) & $1.54( \pm 0.12)^{*}$ & $0.79( \pm 0.05)^{*}$ & $0.40( \pm 0.02)^{*}$ & $0.15( \pm 0.03)^{*}$ \\
\hline Fescue EFKYFA 9301 & $1.59( \pm 0.12)^{*}$ & $0.89( \pm 0.05)^{*}$ & $0.42( \pm 0.02)^{*}$ & $0.17( \pm 0.03)^{*}$ \\
\hline
\end{tabular}

*Significance for Student's $t$ test: $\mathrm{p} \leq 0.05$. 
Table 8 shows that the shoot dry mass of Kentucky bluegrass was not different in any of the ratios tested. Nimblewill showed higher shoot dry mass at the lowest proportion of weed, which was statistically different, demonstrating that it thrives under interspecific competition with Kentucky bluegrass. For all tall fescues, the highest shoot dry mass was at proportions of $50 \%$ and $25 \%$ fescue, indicating that it thrives under interspecific competition, with the exception of tall fescue KYFA 9821 (AR584), which differed only in the smallest proportion of mixtures.

Table 8. Average of the effect of differing proportions of tall fescues, Kentucky bluegrass, and nimblewill plants on shoot dry mass under greenhouse conditions, Lexington, KY, USA, 2009-2010.

\begin{tabular}{|c|c|c|}
\hline Proportions (\%) & Kentucky bluegrass & Nimblewill \\
\hline 100 & 0.14 & 0.26 \\
\hline 75 & 0.11 & 0.24 \\
\hline 50 & 0.12 & 0.27 \\
\hline 25 & 0.16 & $0.39^{*}$ \\
\hline \multirow[t]{2}{*}{$\mathbf{C V}$} & 13.95 & 11.44 \\
\hline & Tall fescue KY 31 & Nimblewill \\
\hline 100 & 0.18 & 0.25 \\
\hline 75 & 0.21 & $0.18^{*}$ \\
\hline 50 & $0.28^{*}$ & $0.14^{*}$ \\
\hline 25 & $0.33^{*}$ & $0.20^{*}$ \\
\hline \multirow[t]{2}{*}{$\mathbf{C V}$} & 14.30 & 12.02 \\
\hline & Tall fescue KYFA 9821 (AR584) & Nimblewill \\
\hline 100 & 0.21 & 0.25 \\
\hline 75 & 0.24 & $0.17^{*}$ \\
\hline 50 & 0.25 & $0.17^{*}$ \\
\hline 25 & $0.39^{*}$ & $0.10^{*}$ \\
\hline \multirow[t]{2}{*}{ CV } & 18.09 & 19.12 \\
\hline & Tall fescue EFKYFA 9821 & Nimblewill \\
\hline 100 & 0.21 & 0.25 \\
\hline 75 & 0.25 & $0.18^{*}$ \\
\hline 50 & $0.31^{*}$ & $0.13^{*}$ \\
\hline 25 & $0.38^{*}$ & $0.11^{*}$ \\
\hline \multirow[t]{2}{*}{ CV } & 12.39 & 18.59 \\
\hline & Tall fescue KYFA 9301 (AR584) & Nimblewill \\
\hline 100 & 0.21 & 0.26 \\
\hline 75 & 0.26 & $0.19^{*}$ \\
\hline 50 & $0.32^{*}$ & $0.13^{*}$ \\
\hline 25 & $0.39^{*}$ & $0.10^{*}$ \\
\hline \multirow[t]{2}{*}{$\mathbf{C V}$} & 14.88 & 16.78 \\
\hline & Tall fescue EFKYFA 9301 & Nimblewill \\
\hline 100 & 0.23 & 0.26 \\
\hline 75 & 0.26 & $0.19^{*}$ \\
\hline 50 & $0.34^{*}$ & $0.14^{*}$ \\
\hline 25 & $0.44^{*}$ & $0.13^{*}$ \\
\hline $\mathbf{C V}$ & 10.15 & 10.44 \\
\hline
\end{tabular}

*Significance for Dunnett's test: $\mathrm{p} \leq 0.05$. 
Nimblewill shoot dry mass was different for the three mixture proportions, with a decrease in dry mass of weed shoots when compared with that of the monoculture (100\%) (Table 8). This indicated that nimblewill lost shoot dry mass in competition with fescue compared with amount of shoot dry mass in a monoculture, suggesting that nimblewill thrives better under intraspecific competition.

\section{Discussion}

From this study, it was possible to observe that there was competition among pasture species tested and nimblewill, which can influence the establishment time of the pastures. During this period (50 d), the tall fescues were more competitive than nimblewill. Competition during pasture establishment is affected by species that tiller early or are spread by stolons, which are also likely to be more aggressive than those with smaller, less-vigorous seedlings or an upright growth habit [5]; however, when sowing such mixtures, some interspecific competition is likely, particularly if species differ in seed size or growth habit [5]. Interspecific competition is influenced by the interaction between plant morphology, defoliation, maturity, and climatic factors [18]. Some of these interactions, which influence the relative persistence of a species, can be examined by replacement series.

In general, species with similar growth habits will make similar demands on the limited resources for growth, but the differences in their efficiency in the utilization of these resources makes one species a better competitor than are the others [19]. Generally, intraspecific competition among crop plants is more severe than the interspecific effects of weeds on crop yield [7].

In another experiment, tall fescue was more effective than perennial ryegrass in competing with and suppressing the colonization of kikuyu grass (Pennisetum clandestinum) [20]. In the greenhouse, Kentucky bluegrass predominated over creeping red fescue (Festuca rubra) at a high level of $\mathrm{N}$ fertilization, but creeping red fescue predominated at a low level of $\mathrm{N}$ fertilization [21].

Allelopathy is another factor that might result in interference of one species over another. In Petri-dish bioassays, tall fescue has been occasionally reported to have allelopathic effects [18] on other species such as birdsfoot trefoil (Lotus corniculatus), red clover (Trifolium pratense), and large crabgrass (Digitaria sanguinalis) [22] [23]. This factor can result in interference of tall fescue with nimblewill, as showed in the results.

The results show that endophyte infection does not reduce the ability of all tall fescues to compete with nimblewill under established conditions. Growth of plants with or without the endophyte was similar in both monoculture and mixture proportions. In contrast to our replacement series experiment, many studies have reported differences in processes between competitive species with or without the endophyte fungi and weeds, and even in intraspecific competition, the tall fescue with endophyte in some cases has a greater disadvantage in the competitive process with other plants.

For perennial ryegrass (Lolium perenne), endophyte infection might be ecologically advantageous in some circumstances but detrimental in others [11]. For example, endophyte infection reduced the ability of perennial ryegrass to compete with large crabgrass and produced fewer tillers and less above-ground biomass than uninfected plants [11]. As a result, endophyte infection might influence the composition of plant communities by altering the competitive hierarchy among plants.

Results a previous study [8] indicated that endophyte infection decreased the performance of perennial ryegrass in both intra- and interspecific competition. In other recent studies, [9] found that endophyte infection had a significant positive effect on ryegrass shoot and root growth, because the plants tended to accumulate more biomass and soluble sugar in the sheath and root than plants that were endophyte free. Endophyte-infected plants have a physiological mechanism that permits better growth, survival, and competitiveness under stressful growth conditions than plants endophyte free [10]. In another study, the dilution of an endophyte pasture with nontoxic grass or legumes showed that the competition between the endophyte pasture and common bermudagrass (Cynodon dactylon) creates an additional stressor for tall fescue. Common bermudagrass and various other grasses and legumes can also provide a measure of natural dilution within many pastures [24]. Given the relative importance of weeds in the agricultural scenario, studies on the biology and the interference relationships of this species on different crops are fundamental [25].

\section{Conclusions}

Under our experimental conditions, Kentucky bluegrass was not a good competitor with nimblewill, but the tall 
fescues (Kentucky 31, KYFA 9821, and KYFA 9301) with the endophyte (strain AR584) and EFKYFA 9821 and EFKYFA 9301 without the endophyte were more competitive with nimblewill. Nimblewill was found to be more competitive than bluegrass, and all tall fescues were more competitive than nimblewill.

This study confirms present recommendations that the presence of an endophyte in three different tall fescues did not alter the competitiveness of these fescues with nimblewill, but the tall fescue Kentucky 31 was more competitive between tall fescues.

Fescues are recommended, especially without the endophytic fungi to suppress nimblewill in implantation of pastures to horses.

\section{References}

[1] Bacon, C.W. and Siegel, M.R. (1988) Endophyte Parasitism of Tall Fescue. Journal of Production Agriculture, 1, 4555. http://dx.doi.org/10.2134/jpa1988.0045

[2] Smith, A.E. (1989) Herbicides for Killing Tall Fescue (Festuca arundinacea) Infected with Fescue Endophyte (Acremonium coenophialum). Weed Technology, 3, 485-489.

[3] Willis, J.B., Beam, J.B., Whitney, L.B., Shawn, D.A. and Mcerroy, J.S. (2007) Selective Nimblewill (Muhlenbergia schreberi) Control in Cool-Season Turfgrass. Weed Technology, 1, 886-889. http://dx.doi.org/10.1614/WT-07-016.1

[4] Baskin, J.M. and Baskin, C.C. (1985) Dormancy Breaking and Germination Requirements of Nimblewill (Muhlenbergia schereberi Gmel.) Seeds. Journal Range Manage, 38, 313-315. http://dx.doi.org/10.2307/3899742

[5] Lodge, G.M., Boschma, S.P. and Harden, S. (2009) Replacement Serie Studies of Competition between Tropical Perennial and Annual Grasses and Perennial Grass Mixtures in Northern New South Wales. Crop and Pasture Science, 60, 526-531. http://dx.doi.org/10.1071/CP08374

[6] Crotser, M.P. and Witt, W.W. (2000) Effect of Glycine max Canopy Characteristic, G. max Interference, and WeedFree Period on Solanum ptycanthum Growth. Weed Science, 48, 20-26. http://dx.doi.org/10.1614/0043-1745(2000)048[0020:EOGMCC]2.0.CO;2

[7] Radosevich, S.R. (1987) Methods to Study Interactions among Crops and Weeds. Weed Technology, 1, 190-198.

[8] Marks, S., Clay, K. and Cheplick, G.P. (1991) Effects of Fungal Endophytes on Interspecific and Intraespecific Competition in the Grass Festuca arundinacea and Lolium perenne. Journal Applied Ecology, 28, 194-204. http://dx.doi.org/10.2307/2404125

[9] Ren, A.-Z., Goa, Y.-B., Wang, W., Wang, J.-L. and Zhao, N.-X. (2009) Influence of Nitrogen Fertilizer and Endophyte Infection on Ecophysioloical Parameters and Mineral Element Content of Perennial Ryegrass. Journal of Integrative Plant Biology, 51, 75-83. http://dx.doi.org/10.1111/j.1744-7909.2008.00721.x

[10] Malinowsky, D.P. and Belesky, D.P. (2000) Adaptation of Endophyte-Infected Cool Season Grasses to Environmental Stress: Mechanisms of Drought and Mineral Stress Tolerance. Crop Science, 40, 923-940. http://dx.doi.org/10.2135/cropsci2000.404923x

[11] Richmond, D.S., Grewal, P.S. and Cardina, J. (2003) Competition between Lolium perenne and Digitaria sanguinalis: Ecological Consequences for Harbouring an Endosymbiotic Fungus. Journal of Vegetation Science, 14, 835-840.

[12] Hoffman, M.L. and Buhler, D.D. (2002) Utilizing Sorghum as a Functional Model of Crop Weed Competition. I. Establishing a Competitive Hierarchy. Weed Science, 50, 466-472. http://dx.doi.org/10.1614/0043-1745(2002)050[0466:USAAFM]2.0.CO;2

[13] Estorninos, L.E., Gealy, D.R. and Talbert, R.E. (2002) Growth Response of Rice (Oryza sativa) and Red Rice (O. sativa) in a Replacement Series Study. Weed Technology, 16, 401-406. http://dx.doi.org/10.1614/0890-037X(2002)016[0401:GROROS]2.0.CO;2

[14] Cousens, R. and O’neill, M. (1993) Density Dependence of Replacement Series Experiments. Oikos, 66, $347-352$. http://dx.doi.org/10.2307/3544824

[15] Bianchi, M.A., Fleck, N.G. and Lamego, F.P. (2006) Proportion among Soybean and Competitor Plants and the Relations of Mutual Interference. Ciência Rural, 36, 1380-1387.

[16] Delwiche, L.D. and Slaughter, S.J. (2003) The Little SAS Book: A Primer. SAS Institute, Cary, 268 p.

[17] Fleming, G.F., Young, F.L. and Ogg, A.G. (1998) Competitive Relationships among Winter Wheat (Triticum aestivium) Jointed Goatgrass (Aegilops cylindrical), and Downy Brome (Brome tectorum). Weed Science, 36, 479-486.

[18] Hill, M.J. and Gleeson, A.C. (1991) Competition between Clare and Seaton Park, and Clare and Daliak Subterranean Clovers in Replacement Series Mixtures in the Field. Australian Journal Agronomy Research, 42, 161-173. http://dx.doi.org/10.1071/AR9910161

[19] Tuor, F.A. and Froud-Willians, R.J. (2002) Interactions between Purple Nutsedge, Maize and Soybean. International 
Journal Pest Management, 48, 65-71. http://dx.doi.org/10.1080/09670870110094369

[20] Elmore, C.L., Gibeault, V.A. and Cudney, D.W. (1997) Invasion Resistance of Tall Fescue (Festuca arundinaceae) (sic) and Perennial Ryegrass (Lolium perene) to Kikuyugrass (Pennisetum clandestinum). Weed Technology, 11, 24-29.

[21] Juska, F.V., Tyson, J. and Harrison, C.M. (1955) The Competitive Relationship of Merion Kentucky Bluegrass as Influenced by Various Mixtures, Cutting Heights, and Levels of Nitrogen. Agronomy Journal, 47, 513-518. http://dx.doi.org/10.2134/agronj1955.00021962004700110006x

[22] Peters, E.J. and Mohammed-Zam, A.H.B. (1981) Allelopathic Effects of Tall Fescue Genotypes. Agronomy Journal, 75, 56-58.

[23] Luu, K.T., Matches, A.G. and Peters, E.J. (1982) Allelopathic Effects of Tall Fescue on Birdsfoot Trefoil as Influenced by N Fertilization and Seasonal Changes. Agronomy Journal, 74, 805-808. http://dx.doi.org/10.2134/agronj1982.00021962007400050009x

[24] Coblentz, W.K., Coffey, K.P., Smith, T.F., Hubbell, D.S., Scarbrough, D.A., Humphry, J.B., Mcginley, B.C., Turner, J.E., Jennings, J.A., West, C.P., Popp, M.P., Hellwig, D.H., Kreider, D.L. and Rosenkrans, C.F. (2006) Using Orchardgrass and Endophyte-Free Fescue versus Endophyte-Infected Fescue Overseeded on Bermudagrass for Cow Herbs: I. Four Years Summary of Forage Caracteristics. Crop Science, 46, 1919-1928. http://dx.doi.org/10.2135/cropsci2005.11-0443

[25] Wandscheer, A.C.D., Rizzardi, M.A. and Reichert, M. (2013) Competitive Ability of Corn in Coexistence with Goosegrass. Planta Daninha, 31, 281-289. http://dx.doi.org/10.1590/S0100-83582013000200005 
Scientific Research Publishing (SCIRP) is one of the largest Open Access journal publishers. It is currently publishing more than 200 open access, online, peer-reviewed journals covering a wide range of academic disciplines. SCIRP serves the worldwide academic communities and contributes to the progress and application of science with its publication.

Other selected journals from SCIRP are listed as below. Submit your manuscript to us via either submit@scirp.org or Online Submission Portal.
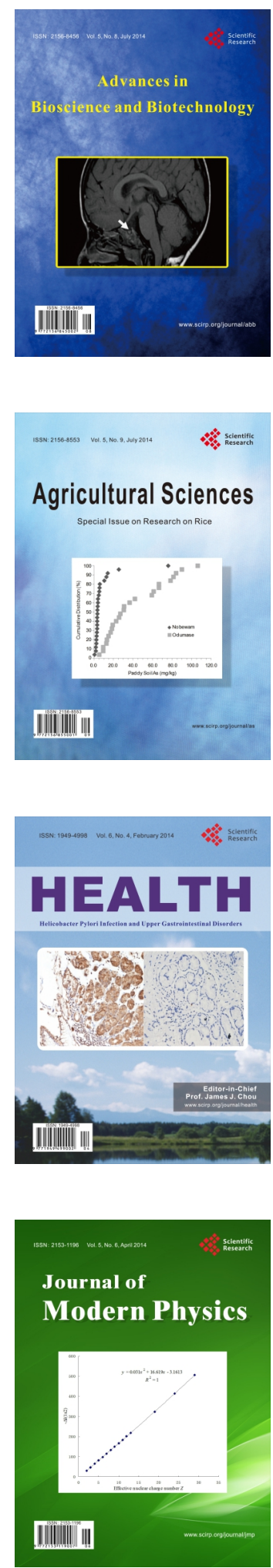
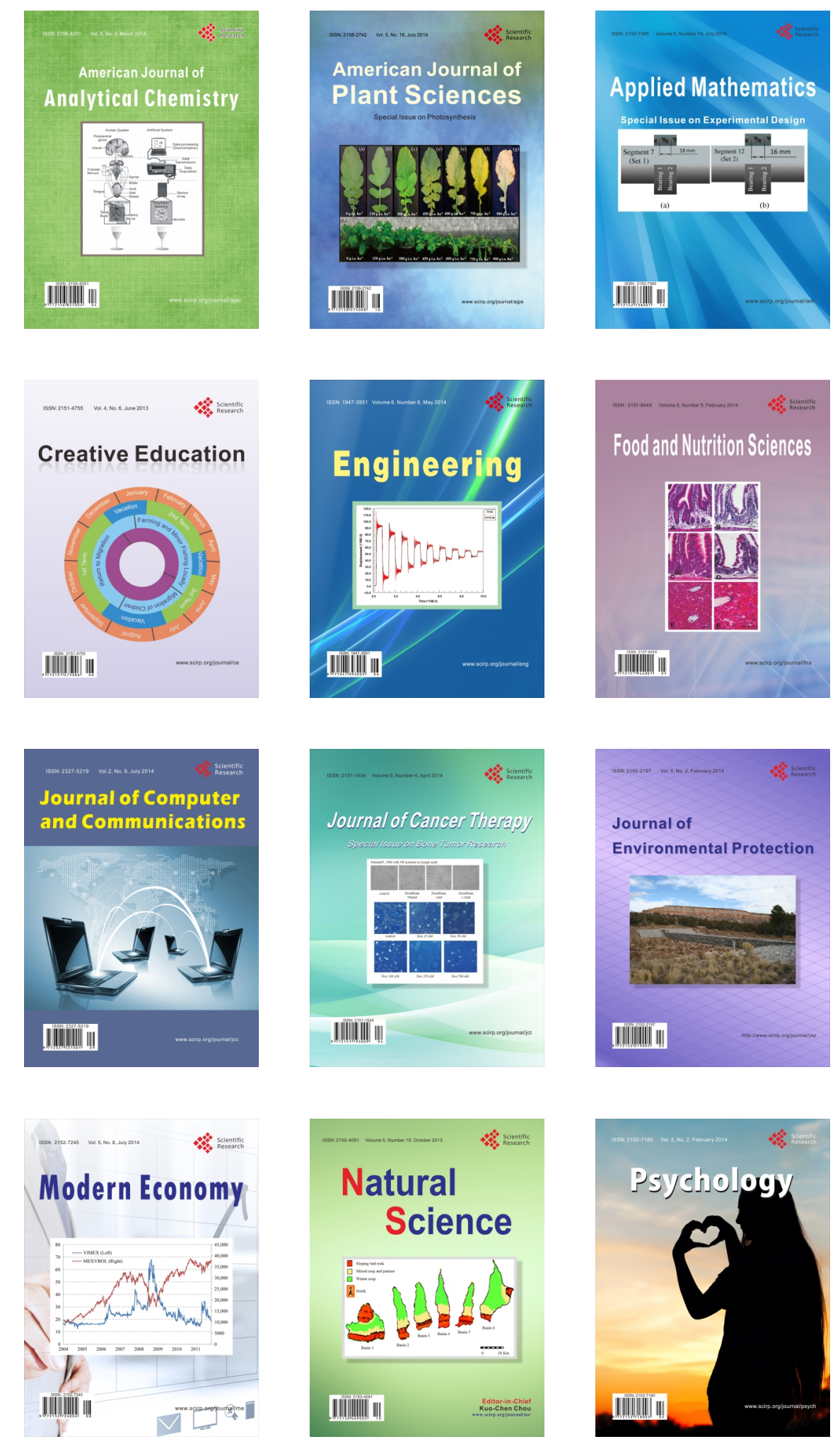